\title{
Mudanças culturais e simbólicas que abalam o Brasil
}

\author{
Cultural and symbolic changes that shake Brazil
}

\author{
Marcelo Ridenti ${ }^{\mathrm{a}}$
}

Resumo Apesar de envolver toda a sociedade, a dinâmica social e política da crise por que passa a democracia brasileira é dada pelas lutas sociais que mobilizam as classes médias escolarizadas. Um forte indício nesse sentido está na composição social das manifestações de rua a partir de 2013 e outros dados analisados no artigo, como o acesso crescente ao ensino superior, resultado de mudanças culturais e simbólicas nos últimos anos, sem que tenham ocorrido transformações estruturais. Essas mudanças ajudam a compreender a polarização política em curso que ameaça a democracia.

Palavras-chave crise da democracia; governos Lula; governo Dilma Rousseff; manifestações de rua pós-2013; classes médias escolarizadas.

Abstract Despite the fact that it involves the whole of society, the social and political dynamics of the present crisis of Brazilian democracy is due to the social struggles that mobilize the middle classes with access to higher education. A strong indication in this sense is the social composition of the street demonstrations from 2013 and other data analyzed by the article, such as the increasing access to higher education, that result from the cultural and symbolic changes in recent years, even if no structural transformation had taken place. These changes help understand the ongoing political polarization which threatens democracy.

Keywords democracy crisis; Lula government; Dilma Rousseff government; post-2013 street demonstrations; middle classes with access to higher education.

a Professor Titular de Sociologia no Instituto de Filosofia e Ciências Humanas da Universidade Estadual de Campinas. 


\section{CONSIDERAÇÕES INICIAIS}

Agradeço aos organizadores do seminário pela iniciativa e pela oportunidade de diálogo nesta noite, buscando compreender aspectos do que se vem passando na sociedade brasileira. ${ }^{1}$ Sem pretender dar conta de toda a complexidade da situação, gostaria de colocar algumas ideias que possam contribuir para o debate.

\section{MUDANÇAS?}

Não parece que tenhamos vivido grandes mudanças estruturais na sociedade brasileira neste século XXI. Nem mesmo os governos liderados pelo Partido dos Trabalhadores (PT) conseguiram implementar reformas de fundo na organização econômica, social e política do Brasil. Não foram realizadas reformas como a agrária, do sistema de tributação, do poder judiciário, de democratização da mídia, do sistema político. A conformação institucional do país segue sendo - no essencial - aquela estabelecida nos anos do regime militar, mesmo após a chamada "constituição cidadã" de 1988, que criou uma série de direitos sociais.

Particularmente nos governos de Lula da Silva (2003 a 2010) e Dilma Rousseff (2011 a 2016), mesmo sem reformas estruturais, foram ampliados significativamente os mecanismos compensatórios de assistência social, como o bolsa família, as farmácias populares, os programas "luz para todos" e "minha casa, minha vida", e ainda melhoraram o acesso à saúde e especialmente ao ensino, inclusive o superior, que - apesar de sua qualidade questionável - se tornou mais permeável também aos mais pobres e aos não brancos. As medidas compensatórias e a expansão econômica permitiram a relativa melhora salarial e de condições de vida dos de baixo. Os referidos governos tenderam a optar por políticas passíveis de encontrar menor resistência política, pretendendo conciliar interesses contraditórios, sem afrontar o sistema, antes buscando desenvolver o capitalismo brasileiro com muito financiamento público e o reforço do mercado interno. A seu modo, trataram ainda de incorporar os despossuídos na pauta política institucional, buscando integrá-los melhor à ordem estabelecida.

Tudo isso ajudou a tirar setores populares significativos da situação de miséria absoluta e a gerar alguma ascensão social, bem como a gerar enormes expectativas em relação ao futuro, otimismo que era compartilhado pelas classes dominantes,

1 Palestra apresentada na mesa de encerramento do evento "Golpe na cultura: intelectuais, universidade pública e contextos de crise”. Seminário de Sociologia da Cultura: Objetos e perspectivas. Programa de Pós-graduação em Sociologia. FFLCH, USP. São Paulo, 9 de dezembro de 2016. Este artigo mantém a forma original de exposição, apenas atualizando alguns dados e acrescentando algo da conjuntura mais recente nas considerações finais. 
as que mais ganharam com o avanço econômico durante as administrações do PT. Como se sabe, a situação econômica e política mudou recentemente, inviabilizando as expectativas de ganhos para todos, gerando frustação social inédita, que se expressou em manifestações de rua numerosas e com muita participação a partir de junho de 2013 .

Sem poder ou querer realizar reformas de fundo que alterassem a estrutura social, a opção pela linha de menor resistência acabou gerando uma realidade política nova, a partir de mudanças culturais e simbólicas, por exemplo, com o aumento da escolaridade e o acesso à informática para a maior parte da população, incluindo setores mais pobres e não brancos que passaram a partilhar um espaço antes exclusivo das classes médias e altas. A noção democrática da universalização dos direitos sociais, posta na Constituição de 1988 e desenvolvida sobretudo nos governos petistas - mas sem que houvesse reformas estruturais que de fato diminuíssem a concentração de renda e as desigualdades - tende a gerar certa frustração, sobretudo nos setores sociais médios com acesso ao ensino superior, onde se pode detectar expectativa, insegurança e insatisfação com a situação nova criada.

\section{UMA HIPÓTESE E ALGUNS DADOS ESTATÍSTICOS: AS CLASSES MÉDIAS ESCOLARIZADAS NA CENA POLÍTICA}

A hipótese que proponho é que - apesar de envolver toda a sociedade - a dinâmica social e política da crise porque passa a democracia brasileira é dada pelas lutas sociais que mobilizam as classes médias escolarizadas. Um forte indício nesse sentido está na composição social das manifestações de rua a partir de 2013. Elas apresentam notáveis semelhanças, como indicam os dados abaixo, referentes a manifestações ocorridas em São Paulo, como a de 20 de junho de 2013 - gigantesca e com um caráter amplo de protesto -, a enorme manifestação de direita contra a presidente Dilma Rousseff em 13 de março de 2016, e a resposta expressiva de esquerda no dia 18 do mesmo mês. Nas três manifestações - que destaco por terem sido as que contaram com dezenas de milhares de participantes - quase $80 \%$ dos que foram às ruas tinham acesso ao ensino superior, bem acima dos $28 \%$ da população paulistana em geral. A escolaridade secundária nos três atos também apresenta percentuais parecidos entre eles, cerca de um quinto dos participantes. Atesta-se, assim, que foram os setores escolarizados os que mais se mobilizaram, independentemente da posição política. 


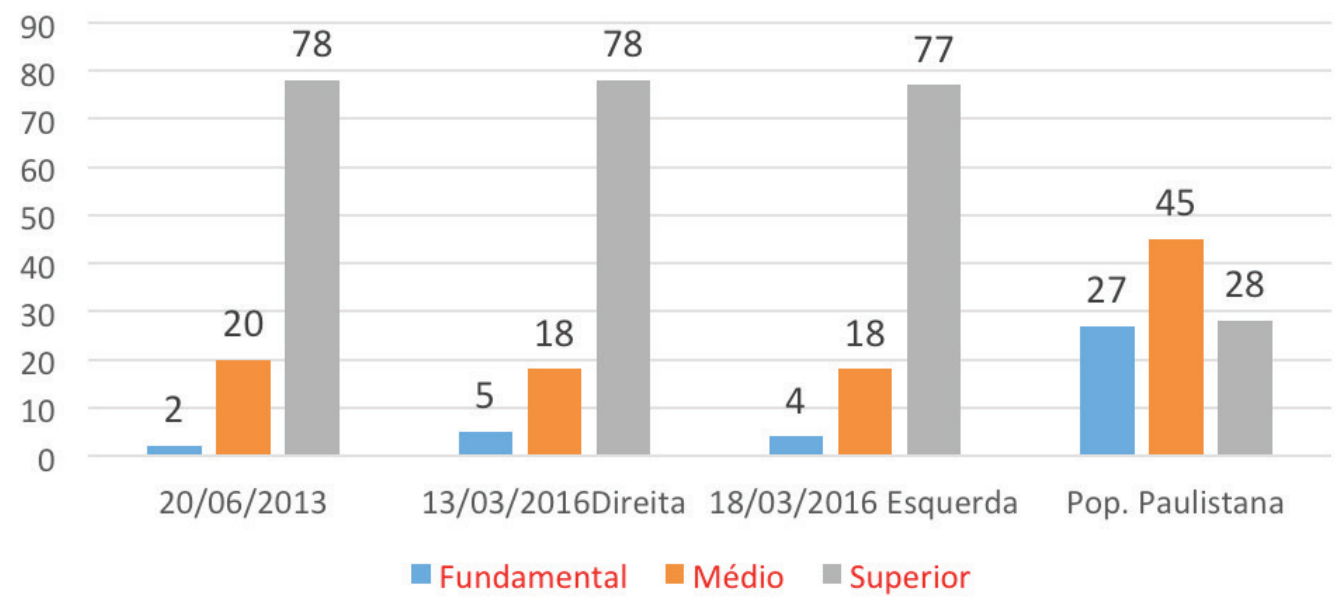

Gráfico 1. Manifestações em São Paulo, Av. Paulista - Escolaridade (Fonte: DataFolha).

Por sexo, os números também estão próximos, em torno de 60\% de participação masculina e 40\% feminina:

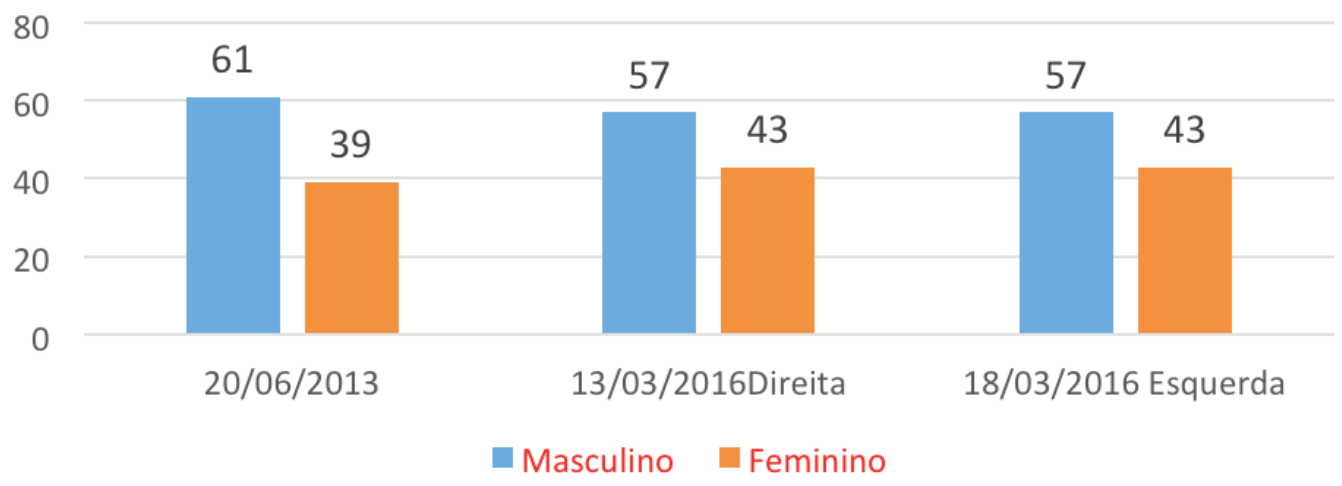

Gráfico 2. Manifestações em São Paulo, Av. Paulista - Sexo (Fonte: DataFolha).

No que se refere à idade, surgem diferenças: a manifestação de 2013 foi integrada pelos mais jovens: $51 \%$ até 25 anos de idade, $84 \%$ até 35 anos. Já a direita contou com os mais velhos: $40 \%$ acima de 50 anos e $83 \%$ acima de 35 , quase o espelho oposto. Por sua vez, o ato de esquerda teve certo equilíbrio: cerca de um quarto para cada grupo: até 25 anos, de 26 a 35, de 36 a 50, e de 51 anos ou mais. 


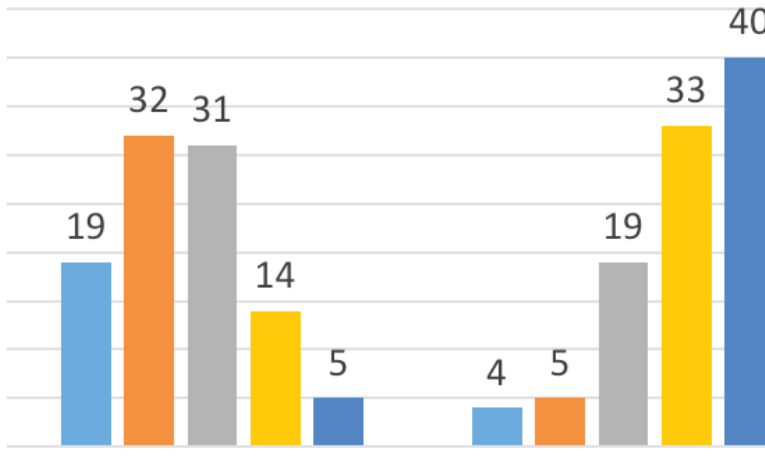

$20 / 06 / 2013$

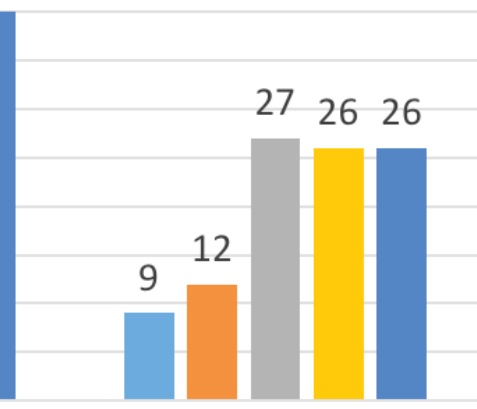

18/03/2016 Esquerda

घ 12 a $20 \quad 21$ a $25 \quad 26$ a $35 \quad$ - 36 a $50 \quad$ - 51 ou +

Gráfico 3. Manifestações em São Paulo, Av. Paulista - Idade (Fonte: DataFolha).

Os números referentes à renda dos participantes - com base em pesquisas do DataFolha e agora também do IBOPE - apresentam diferenças, sendo os direitistas paulistanos os mais ricos (63\% recebendo mais de 5 salários mínimos ao mês), enquanto em todo o Brasil os manifestantes de 2013 eram os mais pobres (45\% ganhando até 5 salários mínimos). Mas, conforme os dados a seguir, nota-se que as manifestações de 2013 em várias cidades também foram as que tiveram maior número de participantes com renda superior a dez salários mínimos, 23\%, atestando o caráter multifacetado daquele evento, que reuniu tanto os setores escolarizados mais ricos como os mais pobres.

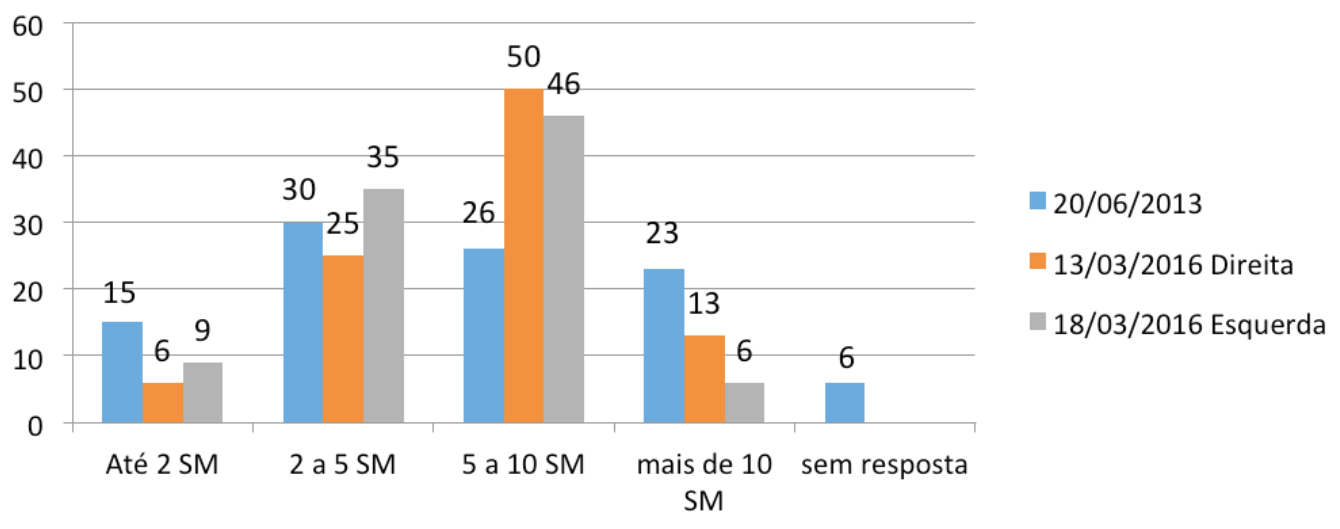

Gráfico 4. Manifestações no Brasil - Renda (Fontes: DataFolha, 2016, em São Paulo; IBOPE, 2013, no Brasil).

Comparando os dados por idade, renda, sexo e escolaridade, verifica-se a participação central dos setores escolarizados, e um pouco mais masculinos, nas três grandes manifestações. Entretanto, elas tiveram discrepâncias significativas no que se refere à renda e à idade. Então, cabe tentar compreender os vetores 
diferenciados que levaram tanta gente das camadas médias escolarizadas às ruas nos últimos tempos, em atos com sentidos políticos diferentes.

Essas manifestações expressam um processo cultural que vem ao menos desde o fim dos anos 1950, que foi acelerado no novo século. Ele envolve ao mesmo tempo a democratização (expansão do acesso à educação e à cultura), e a massificação (submissão à racionalidade da sociedade produtora de mercadorias), no contexto de modernização periférica, com a ampliação do público e do mercado cultural, com a generalização da lógica produtiva de bens simbólicos da indústria cultural.

\section{ACESSO RECORDE AO ENSINO SUPERIOR}

Esse processo pode ser detectado pelo aumento no acesso ao ensino superior, conforme os dados do gráfico a seguir, que expressam bem o salto enorme no século XXI: para uma população brasileira que era de cerca de 70 milhões em 1960 (com menos de 100 mil universitários), e de 170 milhões de pessoas em 2000 (com pouco mais de dois milhões e meio de universitários), chegou-se em 2013 a mais de sete milhões de estudantes no ensino superior para uma população em torno de 201 milhões, contando também os números do ensino à distância. O total de matriculados chegou a mais de oito milhões em $2015 .{ }^{2}$ Um salto que - conforme minha hipótese - está no centro das mudanças culturais e simbólicas que vêm abalando a sociedade brasileira, mesmo sem mudanças de fundo econômicas ou institucionais. Ele envolve um processo de ampliação de direitos que não cabe mais na armadura institucional vigente. O salto lembra em proporção o aumento ocorrido nos anos 1960, que esteve na base da agitação cultural e política do período. Mas agora em números absolutos muito maiores. Naquela oportunidade, junto com a repressão, houve o chamado "milagre econômico", que deu emprego aos contingentes formados, os quais, não obstante, seguiram em parte como críticos da ditadura.

2 Em decorrência da crise econômica e institucional, esse número estancou em 2016, conforme matéria da Folha de S. Paulo, com dados do Censos Educação Superior do MEC ("Ensino Superior tem estagnação de matrículas inédita desde 2006”, 01/09/2017, p. B6). 


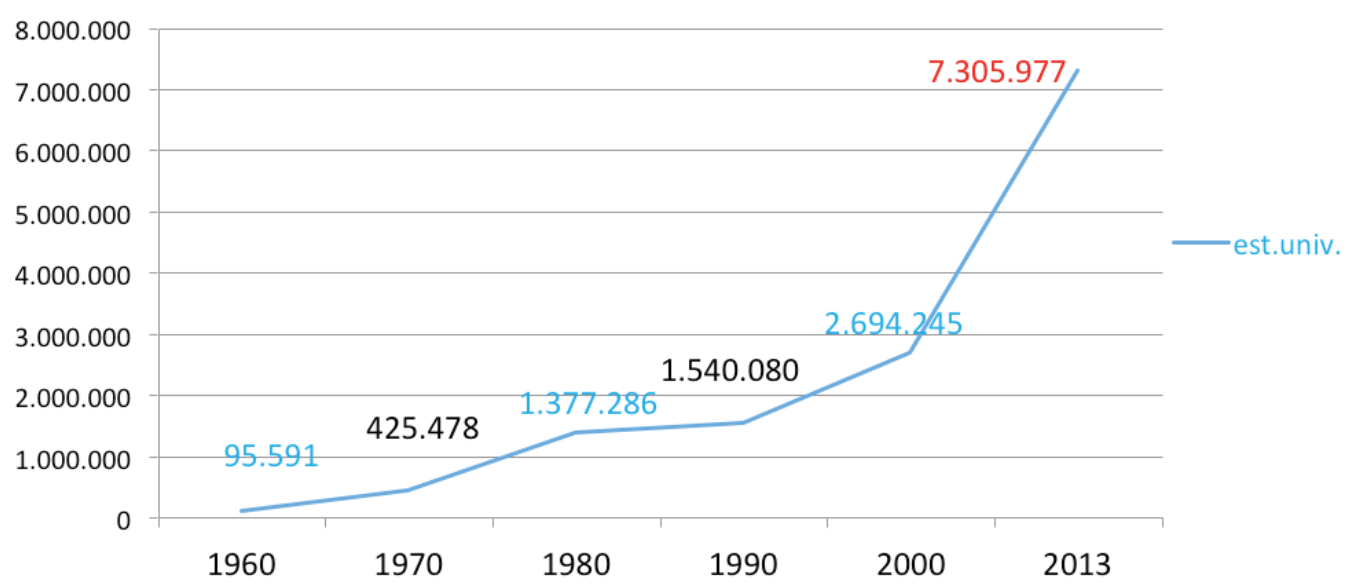

Gráfico 5. Universitários no Brasil (Fonte: MEC - Censos Educação Superior).

A maior parte dos estudantes universitários está no setor privado, em escolas de qualidade acadêmica questionável, muitas vezes em cursos como Pedagogia e Administração de Empresas, de baixo custo para os empresários do setor e que raramente se adequam aos padrões acadêmicos desejáveis. Mas também houve notável expansão do sistema universitário público, como atestam os dados abaixo:

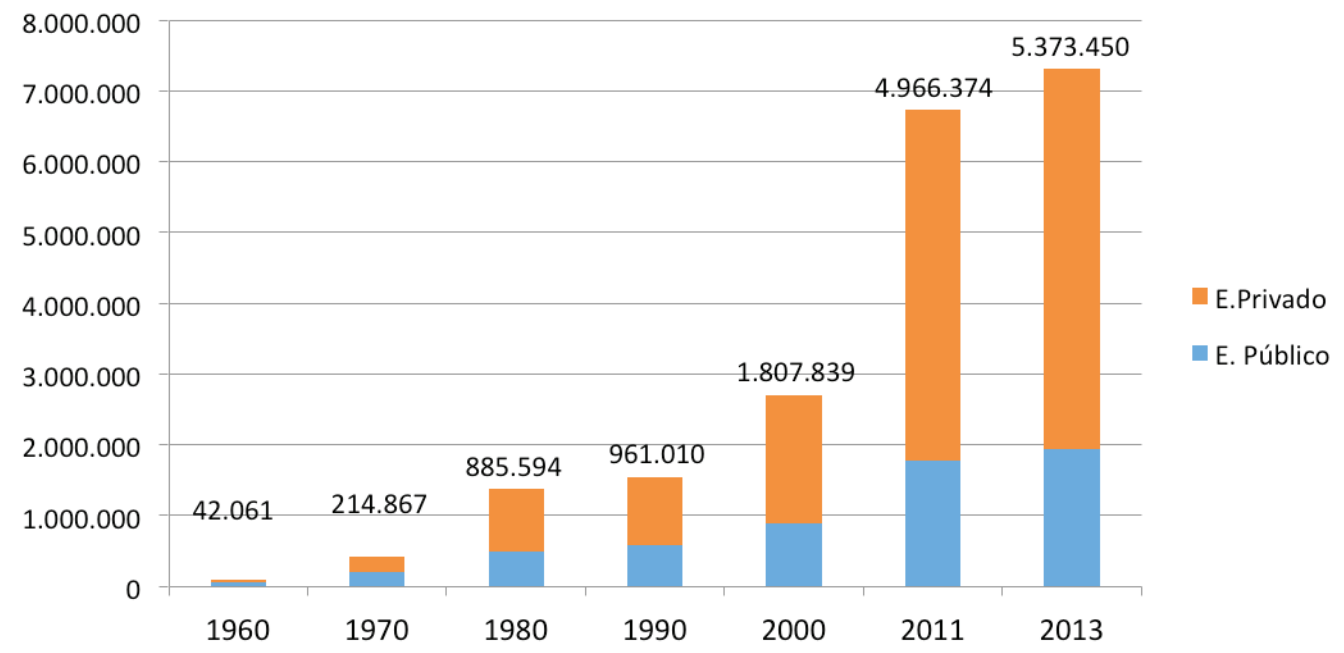

Gráfico 6. Universitários no Brasil (fonte: MEC - Censos Educação Superior).

Nota-se que, em 2013, o ensino privado atendia a mais de 73\% do alunado, confirmando a tendência que vinha do tempo da ditadura militar, quando os matriculados na escola pública passaram a ser minoria. De 2000 a 2013, os matriculados nas escolas privadas quase triplicaram, mas também houve aumento do ensino estatal, que mais do que dobrou o número de alunos atendidos em menos de 15 anos, chagando a quase dois milhões em 2013. 
Esse tipo de expansão do ensino tende a apresentar problemas, como desistência de muitos alunos antes de terminar o curso, seja por dificuldades para acompanhar, seja pela falta de recursos, com revelam os dados a seguir, que apontam para uma evasão escolar de mais de 17\% no ensino público, chegando a mais de $27 \%$ no privado.

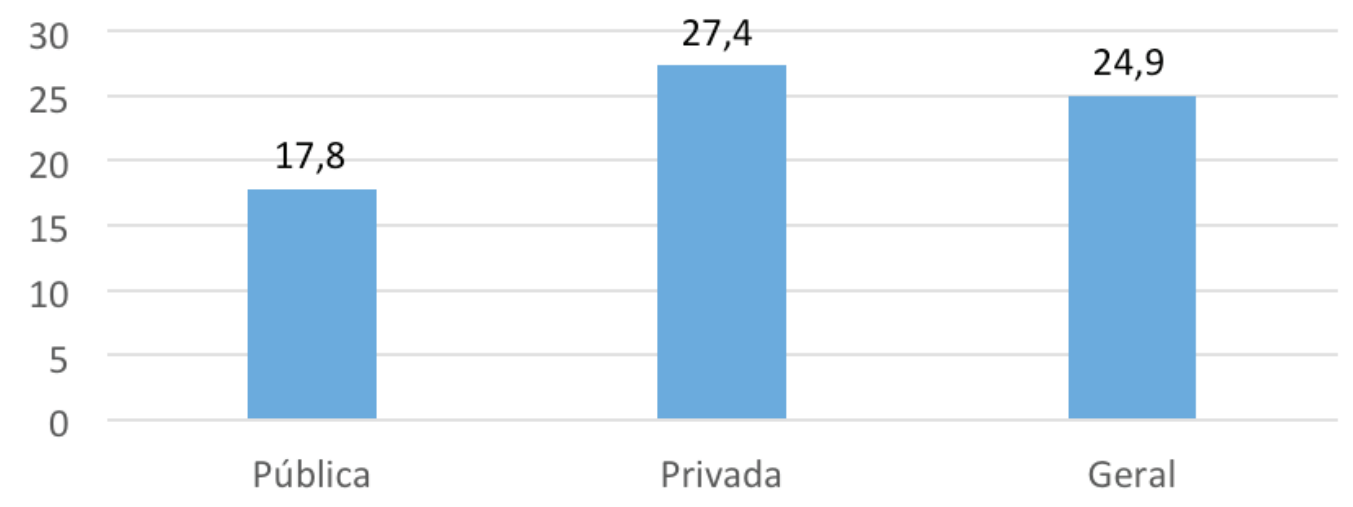

Gráfico 7. Taxa de evasão no ensino superior presencial (Fonte: Mapa do Ensino Superior no Brasil - 2015) ${ }^{3}$.

A área de educação universitária é um bom exemplo da política dos governos federais comandados pelo PT: optaram pela conciliação de interesses contraditórios a fim de encontrar menor resistência. No caso, houve ampliação tanto do ensino superior público como do privado, mantendo-se a estrutura estabelecida no setor. Buscava-se agradar a todos com mudanças pontuais, sem mexer nas estruturas, cativando tanto os donos das escolas - que ganhavam muito com o financiamento dos estudantes pelo governo - como os alunos pobres e suas famílias que, frequentemente, pela primeira vez em gerações, conseguiam ter um membro na universidade, não raro no ensino público, beneficiados por uma política crescente do estabelecimento de cotas para não brancos e de baixa renda. Os dados a seguir, de 2013, são expressivos: quase 30\% dos universitários eram os primeiros de suas famílias a entrar no ensino superior. E 56\% do total era de alunos que estudaram no segundo grau em escola pública.

3 Assessoria Econômica do Sindicato das Mantenedoras de Ensino Superior, p.12, http://convergenciacom.net/pdf/mapa-ensino-superior-brasil-2015.pdf. Consulta realizada em 3 de dezembro de 2017. 
Em que tipo de escola cursou o ensino médio?

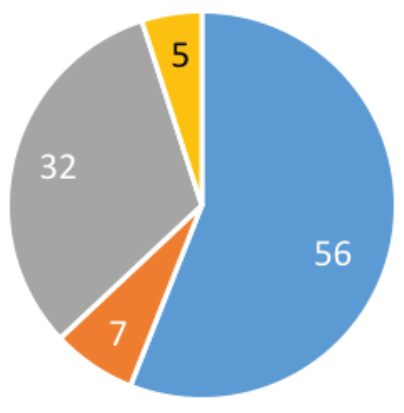

- Escola Publica = > Parte E. Pública

- Escola Privada $\quad$ > Parte E. Privada
Alguém em sua família concluiu o ensino superior?

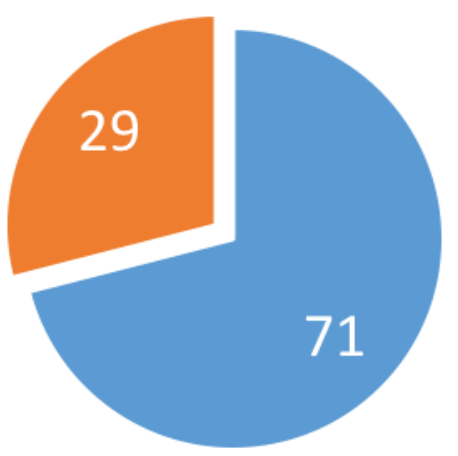

Gráfico 8. Origem dos universitários no Brasil (Fonte: Censo da Educação Superior 2013)4.

Ainda mais surpreendente é o aumento do acesso de não brancos ao ensino superior. Mesmo que os brancos sigam sendo maioria, a participação dos negros na universidade (8\%) já equivale a sua presença proporcional na população. Os autodeclarados pardos, pouco mais de $43 \%$ da população em geral, constituem 31\% dos universitários, como revelam os dados abaixo:

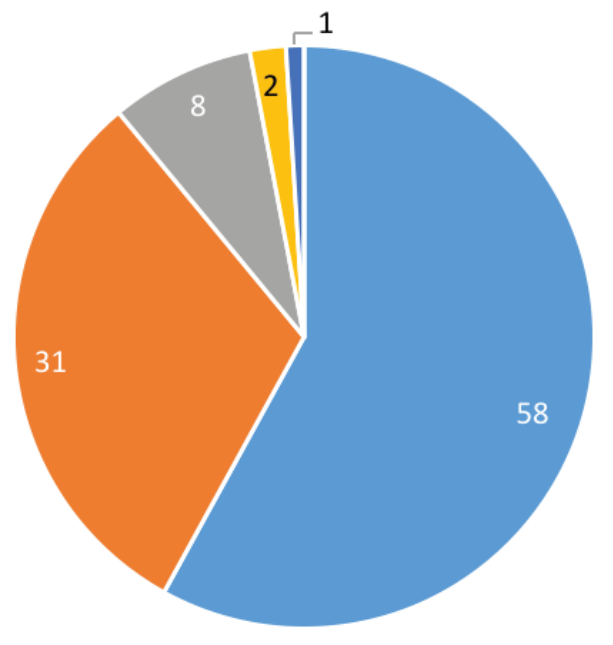

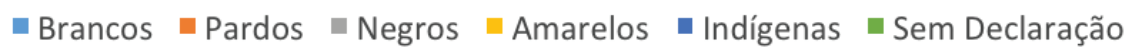

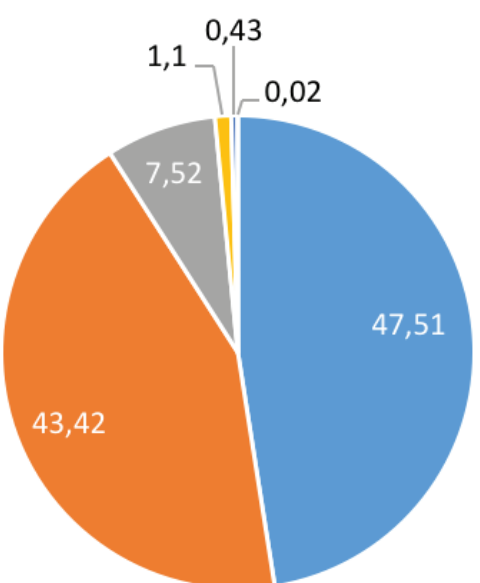

Gráfico 9. Distribuição étnica no Brasil - Alunos do Ensino Superior (Fonte: Censo E. Superior 2013); População em geral (Fonte: Censo IBGE, 2010).

4 Acesso e Permanência no Ensino Superior, José Francisco Soares (Presidente do INEP), http://portal. mec.gov.br/index.php?option=com_docman\&view=download\&alias=17199-cne-forum-educacao-superior-2015-apresentacao-10-jose-soares\&Itemid=30192. Consulta realizada em 3 de dezembro de 2017. 
Essa inclusão social não alterou a organização do ensino superior privado como um negócio, que nesse contexto se tornou um dos mais rentáveis, envolvendo bilhões de reais, seguindo a mesma tendência geral de concentração de capital dos demais ramos da economia, e ainda com incentivos do governo. Os dados a seguir expressam a magnitude do empreendimento:

Tabela 1. Maiores grupos educacionais privados do Brasil (Fonte: Hoper Educação; Folha de S. Paulo, 29/06/2017, p. A24).

\begin{tabular}{|c|c|c|c|}
\hline & $\begin{array}{c}\text { Receita líquida } \\
\text { (em milhões de reais)* }\end{array}$ & $\begin{array}{l}\text { Matrículas } \\
\text { em 2016** }\end{array}$ & $\begin{array}{l}\text { Participação no } \\
\text { mercado (\%) }\end{array}$ \\
\hline $\begin{array}{l}\text { Kroton } \\
\text { (inclui Anhanguera, Unopar, Fama, } \\
\text { Pitágoras, Uniderp) }\end{array}$ & $5 \cdot 244,70$ & 877.033 & 14,4 \\
\hline $\begin{array}{l}\text { Estácio } \\
\text { (inclui Uniseb) }\end{array}$ & $3.184,50$ & 436.300 & 7,2 \\
\hline Unip & $2.641,60$ & $403 \cdot 358$ & 6,6 \\
\hline $\begin{array}{l}\text { Laureate } \\
\text { (inclui Anhembi-Morumbi, FMU, } \\
\text { UniNorte) }\end{array}$ & $2.111,40$ & $245 \cdot 921$ & 4,1 \\
\hline $\begin{array}{l}\text { Ser Educacional } \\
\text { (inclui Univeritas) }\end{array}$ & $1.125,40$ & 137.194 & 2,3 \\
\hline Uninove & 810,40 & 131.733 & 2,2 \\
\hline Cruzeiro do Sul Educacional & 573,20 & 102.286 & 1,7 \\
\hline Anima & $1.076,30$ & 85.138 & 1,4 \\
\hline Devry & 800,00 & 75.000 & 1,2 \\
\hline Unicesumar & 379,00 & 66.960 & 1,1 \\
\hline TOTAL DO SETOR PRIVADO & $54.874,70$ & 6.071 .429 & \\
\hline
\end{tabular}

*estimativa; **presencial e à distância.

Os grupos Anhanguera e Kroton fundiram-se em 2013, quando eram os dois maiores no ramo. Em 2016, o grupo Kroton fez oferta de R $\$ 5$ bilhões para adquirir o vice-líder (Estácio), disputando a compra com o Ser Educacional. A transação acabou por não ser realizada, pois não obteve o aval do Conselho Administrativo de Defesa Econômica (CADE), órgão do governo federal, que vetou o negócio para evitar o excesso de concentração num "mercado potencial de 12 milhões de alunos no segmento", segundo a Folha de S. Paulo (29/06/2017, p. A24). Mas os dados dão uma ideia do montante envolvido no setor, que tem contado com apoio do Estado. Vejam-se, por exemplo, alguns números do Fundo de Financiamento Estudantil (FIES) do Ministério da Educação (MEC): 


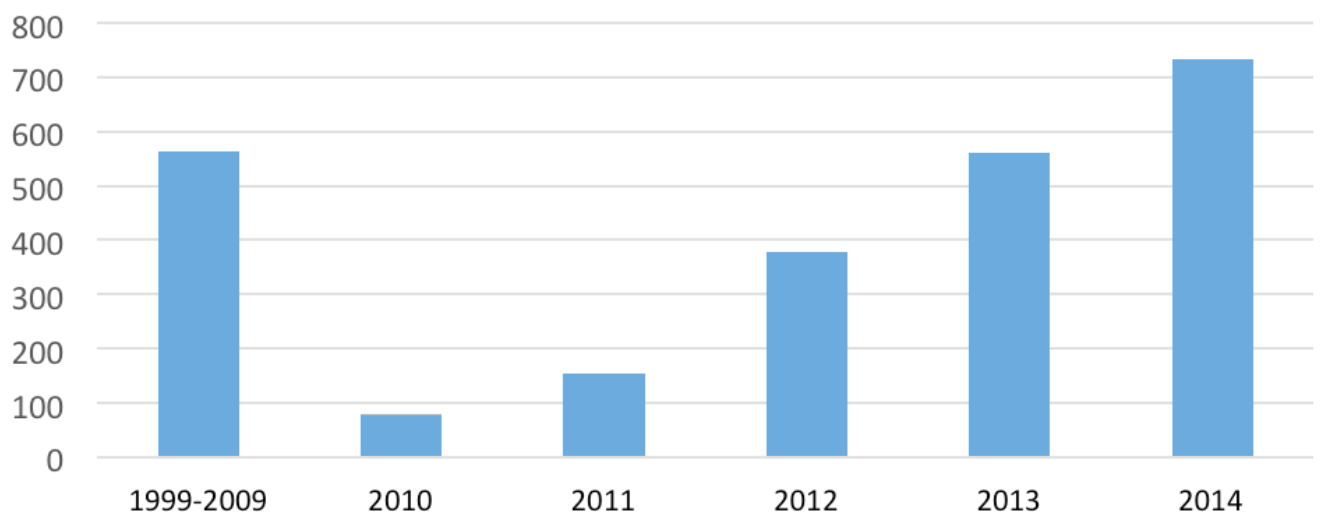

Gráfico 10. Contratos firmados - FIES, em milhares (Fonte: Mapa do Ensino Superior no Brasil, 2015)5.

Os dados apontam o forte investimento do Estado. Os mais críticos diriam que, assim, o governo financia e compactua com o sistema de ensino privatizante e de baixa qualidade, que vende ilusões de ascensão social. Mas essa política abriu as portas da universidade a milhares de jovens das camadas populares, especialmente as não-brancas.

Outros indicadores de investimento no estudantado dizem respeito à internacionalização, como constatou o Portal Terra: o número de brasileiros que realizaram estudos no exterior aumentou 500\% na última década e, apenas em 2014, cerca de 230 mil jovens estudaram fora do Brasil, informou nesta segunda-feira a Associação Brasileira de Organizações de Viagens Educacionais e Culturais (Belta). A maioria dos brasileiros busca aprender ou aperfeiçoar uma segunda língua, mas, nos últimos anos, aumentou de maneira notável o número de jovens que fazem um curso universitário fora do país. De acordo com a Belta, isto foi possível, em parte, graças ao programa Ciências Sem Fronteiras, que desde 2011 ofereceu bolsas de estudos em universidades estrangeiras para mais de 83 mil estudantes do Brasil, em centros universitários de países como Canadá, Estados Unidos e Austrália. ${ }^{6}$

Ou seja, especialmente nos governos de Lula e Dilma, houve um inusitado aumento de investimento governamental no ensino superior. Surge uma juventude crescentemente escolarizada e que trabalha. Mas não se deve esquecer que cerca $70 \%$ dos jovens entre 18 e 24 anos não estavam na escola, conforme levan-

5 Assessoria Econômica do Sindicato das Mantenedoras de Ensino Superior, p.14. http://convergenciacom.net/pdf/mapa-ensino-superior-brasil-2015.pdf. Consulta realizada em 3 de dezembro de 2017.

6 Portal Terra, 9/3/2015, http://noticias.terra.com.br/educacao/numero-de-brasileiros-que-estudam-no-exterior-aumenta-500-em-uma-decada,1ca7c3e8ddooc410VgnCLD20000ob1bf46doRCRD.html. Consulta realizada em 3 de dezembro de 2017. 
tamento do Ipea para 2009 (com base no Pnad/IBGE). Muitos deles deverão estar nos bancos escolares nos próximos anos, outros serão "nem, nem" (nem escola, nem trabalho). Seja como for, há uma tendência à mudança na escolaridade da população e no perfil dos trabalhadores, cada vez mais escolarizados e com acesso crescente à tecnologia nas comunicações e na cultura, apesar dos limites qualitativos do processo.

\section{DADOS DA DEMOCRATIZAÇÃO E MASSIFICAÇÃO DA CULTURA}

A velocidade do processo de democratização e massificação da cultura pode ser detectado por indicadores como o acesso acelerado ao uso de telefones celulares, que em menos de dez anos passou de cerca de um terço para mais de dois terços da população, conforme os dados seguintes:

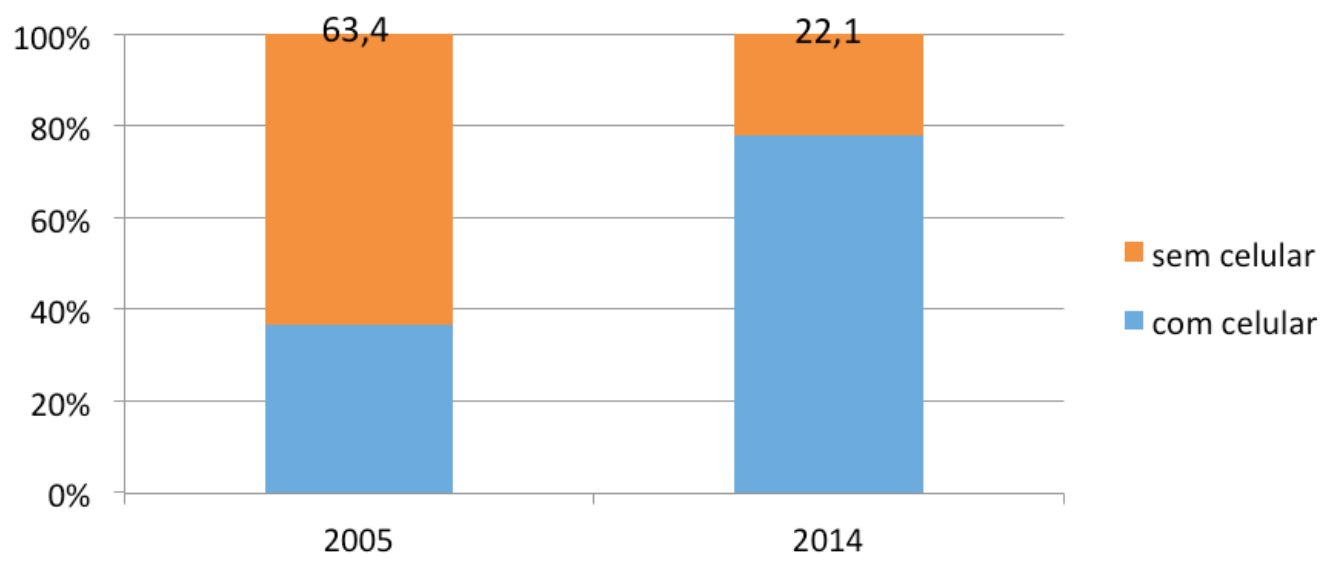

Gráfico 11. Proprietários de telefone celular pessoal, em \% da população com mais de 10 anos (Fonte: IBGE/PNAD 2015).

Um outro aspecto muito notado, com fortes implicações simbólicas, tem sido o aumento no número de passageiros em voos pelo Brasil, que foi da ordem de 170\% em dez anos, a contar de 2004. Uma pesquisa da Secretaria de Aviação Civil apontou que 117 milhões de passageiros voaram de avião em rotas nacionais em 2014, conforme matéria do R7 Notícias, de 22/10/2015.7

$\mathrm{O}$ rápido aumento do número de brasileiros com acesso à internet também é expressivo das mudanças culturais e simbólicas em curso. Houve um salto de

7 http://noticias.r7.com/brasil/numero-de-passageiros-em-voos-pelo-brasil-cresceu-170-em-dez-anos-22102015 Consulta realizada em 3 de dezembro de 2017. 
35 para 120 milhões de pessoas nesse quesito, entre 2006 e 2014, conforme os dados a seguir:

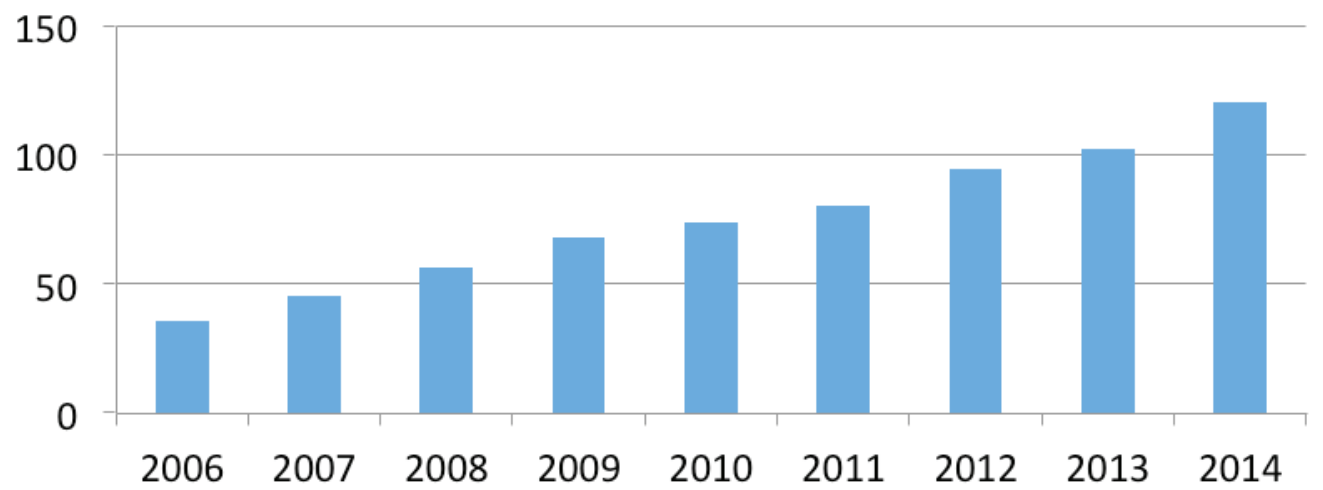

Gráfico 12. Acesso à internet no Brasil, em milhões de pessoas (Fonte: IBOPE).

Esse acesso crescente da população à internet - que é uma característica mundial do capitalismo na era digital - ajuda a entender as mobilizações para as manifestações de rua recentes. Por exemplo, dados do IBOPE referentes à participação em atos de protesto em oito capitais no dia 20/6/13 apontam que 62\% dos participantes souberam das manifestações por intermédio do Facebook:

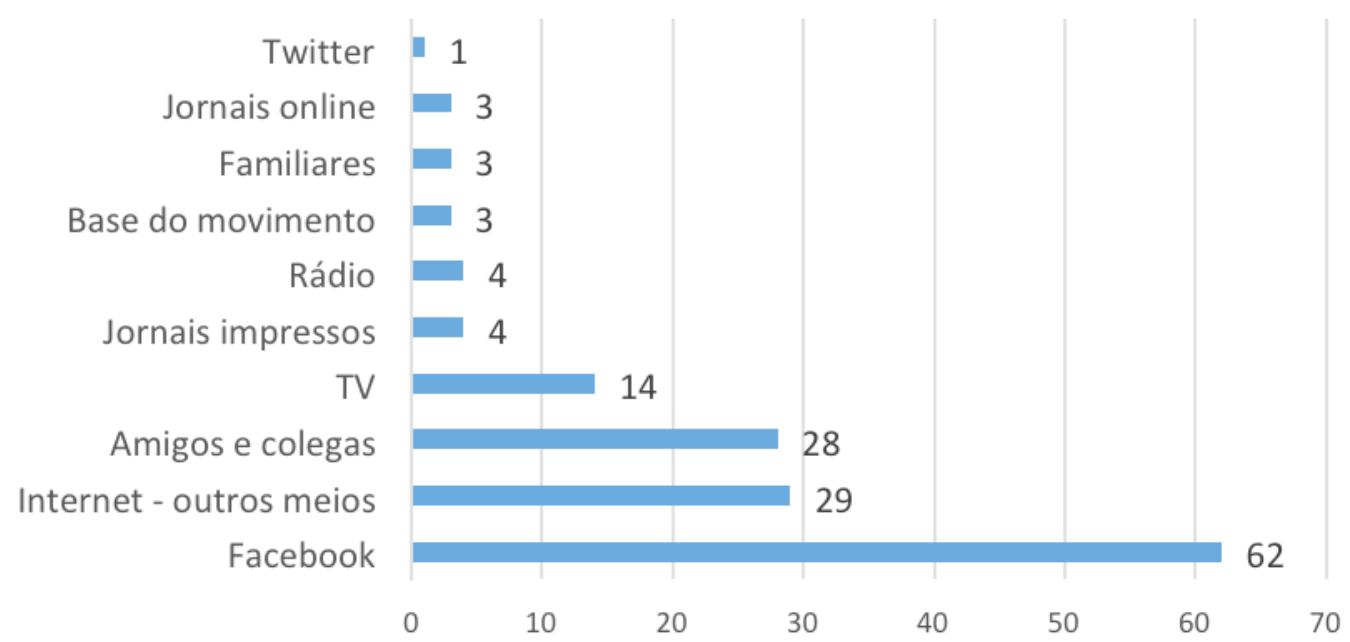

Gráfico 13. Como soube da realização da manifestação de hoje? (Fonte: IBOPE) ${ }^{8}$.

O aumento do uso da internet para informação é expressivo, enquanto jornais e revistas são cada vez menos usados. Mas o rádio e especialmente a televisão seguem sendo os meios mais utilizados, como indicam os dados a seguir:

8 Disponível em http://especial.g1.globo.com/fantastico/pesquisa-de-opiniao-publica-sobre-os-manifestantes/. Consulta realizada em o1 de fevereiro de 2017. 


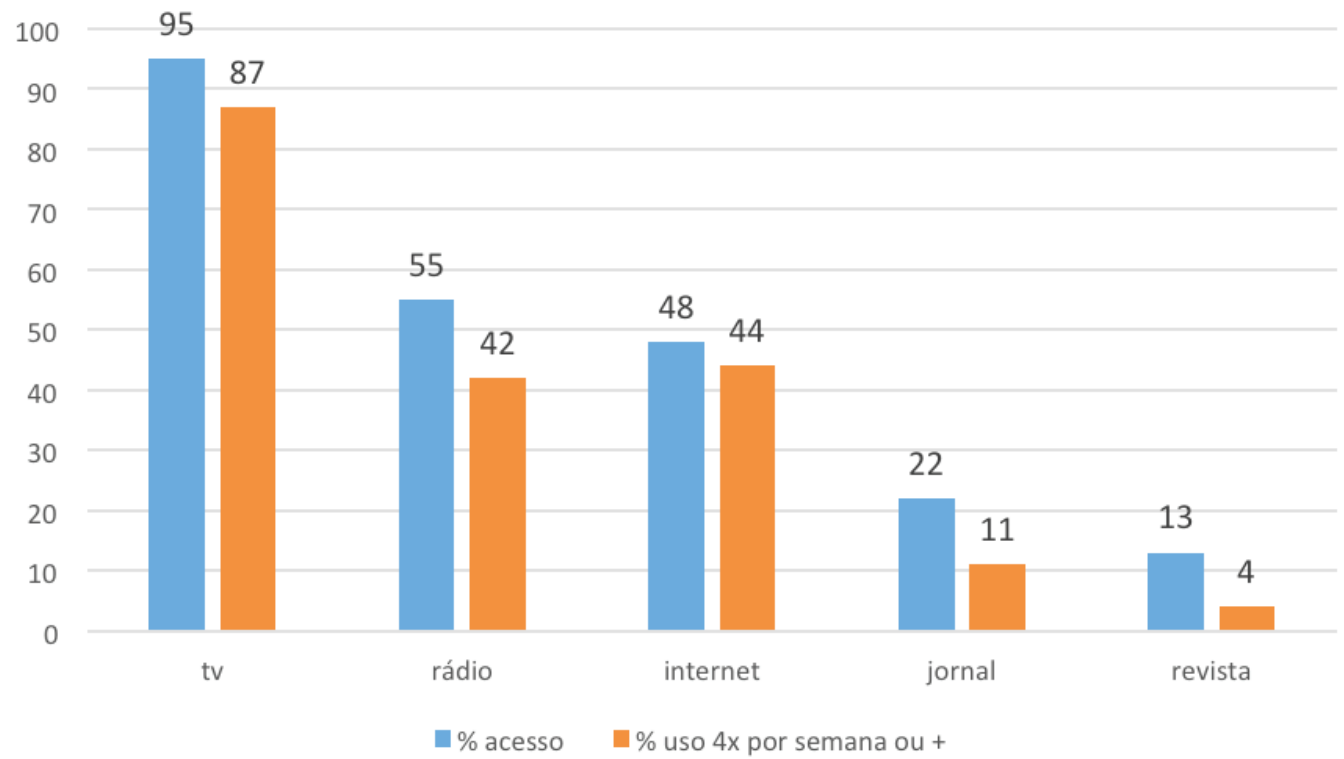

Gráfico 14. Uso dos meios de comunicação no Brasil, 2015 (Fonte: Brasil. Presidência da República. Secretaria de Comunicação Social. Pesquisa brasileira de mídia 2015: hábitos de consumo de mídia pela população brasileira. - Brasília: Secom, 2015 (IBOPE, mais de 18 mil entrevistas) $)^{9}$.

A televisão continua muito assistida no país, por 95\% da população. 87\% assistem quatro dias por semana ou mais, sendo que $73 \%$ ligam o aparelho todos os dias. Em média, cada telespectador vê quatro horas e 31 minutos por dia da semana e quatro horas e 14 minutos nos finais de semana. 79\% dizem que usam a televisão "para se informar, saber as notícias" (Brasil, 2015: 15-28). Justamente por isso é o meio que mais atrai investimentos em publicidade. Em segundo lugar vem o rádio, com $55 \%$.

Ou seja, o poder de comunicação do rádio e especialmente da televisão segue sendo muito expressivo, mas é um terceiro meio que vem tendo audiência crescente sobretudo entre os jovens: a internet. Ela já ocupa o segundo lugar, se computadas apenas as pessoas que a acessam quatro vezes por semana ou mais (44\% contra 42\% para o rádio). $48 \%$ dos brasileiros têm acesso à internet, conforme os dados de 2015, 37\% usam o serviço diariamente e $44 \%$ ao menos quatro dias da semana. Os jovens entre 16 e 25 anos são os usuários mais expressivos, 67\% acessam diariamente e apenas 20\% não usam a internet. Dentre as pessoas com ensino superior, só $12 \%$ não a utilizam. O meio é mais acessado proporcionalmente pelos

9 http://www.secom.gov.br/atuacao/pesquisa/lista-de-pesquisas-quantitativas-e-qualitativas-de-contratos-atuais/pesquisa-brasileira-de-midia-pbm-2015.pdf. Consulta realizada em 3 de dezembro de 2017. Todas as referências a esse relatório aparecem entre parênteses, no texto, como "Brasil, 2015". 
mais ricos: $76 \%$ dos que têm renda familiar acima de 5 salários mínimos. O uso é mais frequente quanto maior o porte do município. No geral, cada usuário acessa a internet em média quatro horas e 59 minutos no meio de semana e 4 horas e 24 minutos nos finais de semana. $67 \%$ dos usuários afirmam usar a internet para se informar (Brasil, 2015: 49-64).

Esses indicadores ajudam a entender, por exemplo, a disputa pela cobertura das manifestações de rua de junho de 2013, que questionaram a imprensa, radiofônica e televisiva, identificando nela uma conivência inaceitável com a ordem estabelecida. Cenas de hostilidade a esses meios foram frequentes, como ataques a veículos de redes de televisão. A surpresa com os acontecimentos e a necessidade de competir com as mídias sociais pela informação gerou uma cobertura inédita da imprensa escrita, do rádio e sobretudo da televisão, que se sentiram ameaçados pelo uso da internet e trataram de intervir, buscando influenciar os rumos do movimento. As longas horas ao vivo, dedicadas pelas principais emissoras de televisão, especialmente após as manifestações de rua expressivas nas principais cidades em 17 de junho, em parte mudaram o viés preconceituoso das primeiras coberturas. Elas provavelmente colaboraram para a presença maciça de pessoas nas ruas nos dias seguintes, até quase o final do mês. Assim como ajudaram a mobilizar as massas em favor do impeachment da presidente Dilma em 2016.

\section{CONSIDERAÇÕES FINAIS}

No conjunto, os dados apresentados apontam para mudanças culturais e simbólicas expressivas no século XXI, com a ampliação do acesso à educação e à cultura na era digital, mas de modo massificado. E a estruturação da sociedade brasileira praticamente não mudou: os lugares sociais são os mesmos e cada vez mais disputados. A competição é crescentemente acirrada por vagas nas universidades de qualidade, lugares privilegiados no mercado de trabalho, postos no aparelho de estado, com forte disputa por distinção e prestígio social.

A promessa de ascensão social pelo ensino e a inclusão social pelo consumo - inclusive de bens culturais - geraram muitas esperanças e expectativas nos primeiros anos do século, mas logo seu caráter ilusório se revelou, gerando insatisfação crescente, em especial nos meios intelectualizados. A frustração generalizou-se quando foi ficando claro que as expectativas não se realizariam. Daí as grandes manifestações de rua de 2013 e as que se seguiram, mobilizando sobretudo os setores mais escolarizados. Imbricaram-se o desejo irrealizado de ascensão, realização e reconhecimento dentro da organização da sociedade como ela é, com certa insatisfação com a mercantilização universal da vida cotidiana 
nas condições precárias de trabalho, moradia, saúde, educação e transporte para a maioria. Por exemplo, torna-se cada vez mais difícil pagar planos de saúde e escolas privadas.

Especialmente a juventude escolarizada vem expressando dúvidas sobre a possibilidade de assegurar ao menos o mesmo nível de vida dos pais (para os mais privilegiados), ou ascender socialmente (para os mais pobres). Os dados indicam que se vai gestando uma realidade cultural nova, com altas expectativas que não encontram lugar nem nas instituições (especialmente as políticas), nem na ordem econômica tal qual estabelecida.

Da perspectiva das classes médias estabelecidas - que tradicionalmente ocupam os postos privilegiados do trabalho intelectual, público e privado -, sente-se o risco de perder seus lugares (conquistados por trabalho, mérito ou herança) para os setores emergentes, incluindo não brancos, migrantes internos e minorias. Elas se sentem ameaçadas, até mesmo roubadas, o que se casa com o tema da corrupção, que dá um motivo moral e conscientemente aceitável para o protesto contra a ampliação de direitos sociais, quando não ocorre a adesão aberta a posições racistas, homofóbicas e antidemocráticas.

Entre as camadas intelectualizadas ascendentes, a insatisfação também é grande, mas a perspectiva é outra: detectam que - se há alguma democratização e mobilidade social - elas são muito limitadas. Os anseios de bem-estar rapidamente se chocam com a realidade. As promessas não se cumprem, nem mesmo as de integração social pelo consumo de mercadorias. Os diplomas de nível superior não garantem melhores empregos, nem prestígio ou igualdade social. Esse descontentamento pode levar à busca de transformação mais profunda. Mas a politização é baixa, não raro a insatisfação se volta apenas contra o Estado e os corruptos, fazendo também desses setores ascendentes um solo fértil para práticas antidemocráticas e discursos conservadores.

Essa situação tem gerado respostas à esquerda e à direita. À esquerda, com reivindicações de mudança estrutural, associadas à reinvenção democrática na ocupação do espaço urbano, com o florescimento de movimentos culturais, inclusive nas periferias das grandes cidades (grupos de teatro, criação literária, música, hip-hop, produção audiovisual). Já a direita conseguiu dar o tom predominante ao aprovar o impeachment da presidente Dilma Roussef, com anseios de retorno à ordem tradicional e de retomada do neoliberalismo na economia, não hesitando em tomar atitudes antidemocráticas.

Num contexto de recessão econômica, o temor de alguns de perder espaços de poder, prestígio e privilégios, uniu-se ao medo de outros de não conseguir 
ganhá-los. Sonhos frustrados, os insatisfeitos foram às ruas, manifestaram-se na internet, agindo como podiam, abrindo possibilidades de ampliar a democracia e também para o autoritarismo frutificar.

Acontecimentos recentes atestam essa polarização. O presidente Michel Temer logo encampou a pauta neoliberal e aprovou no Congresso um projeto que congelou os gastos públicos para os próximos governos, por vinte anos, a fim de realizar o chamado "saneamento das contas públicas", com prejuízo para investimentos sobretudo em educação e saúde, sem que tivesse obtido mandato nas urnas para implementar propostas desse teor. Depois patrocinou uma reforma trabalhista que possibilita a troca de empregos formais por contratos temporários ou intermitentes, flexibilizando as relações de trabalho para colocar o mercado em sintonia com a desregulamentação na área em âmbito internacional. Mas não obteve sucesso em sua reforma da previdência. Impopular por sua política econômica e fragilizado por denúncias de corrupção, tratou de imprimir uma intervenção militar para garantir a segurança no estado do Rio de Janeiro, sem planejamento estratégico, que logo foi questionada pelos especialistas em segurança pública e por analistas que viram aí uma jogada política para ganhar popularidade.

A intervenção ficou em xeque sobretudo após o assassinato da vereadora carioca Marielle Franco e de seu motorista Anderson Gomes em março de 2018, provavelmente cometido por inimigos das políticas de direitos humanos e de afirmação popular que ela defendia. Forças de esquerda foram às ruas em protesto em todo o país, mobilizando setores populares para além das classes médias escolarizadas que vinham sendo predominantes nas manifestações. A própria Marielle, negra e favelada de 38 anos, que se formou em Ciências Sociais na PUC do Rio de Janeiro e defendeu o mestrado em Administração na Universidade Federal Fluminense em 2014, encarnava as mudanças culturais e simbólicas referidas neste artigo. Sua trajetória é expressiva do potencial democrático dessas mudanças, e sua execução representa bem a direção oposta.

Nesse contexto, rapidamente as pesquisas passaram a apontar o ex-presidente Lula como favorito para ganhar as eleições presidenciais de 2018, apesar de sua candidatura ser improvável com o cerco de ações judiciais que o tornariam inelegível, sem contar a tradicional má vontade da grande mídia em relação a ele. Lula realizou campanhas mobilizadoras nas ruas em todo o país, sobretudo na região Nordeste, crescendo em suas bases o desejo de um "reformismo forte", em contraste com as reformas modestas de seus governos. Em reação, sua caravana política foi hostilizada e agredida por segmentos de extrema direita no Sul do país, apoiados não só nas camadas jovens escolarizadas referidas - base de mobilizações 
como as do Movimento Brasil Livre (MBL) -, mas também em outros segmentos e classes sociais, como os chamados "ruralistas", classe dos grandes proprietários fundiários. Eles jogaram pedras, ovos, tomates e usaram de outros recursos para inviabilizar a caravana de Lula, até mesmo atirando em um de seus ônibus na passagem pelo Paraná no fim de março. A escalada de extrema direita no país pode ser atestada também pelo aumento nas intenções de voto do candidato Jair Bolsonaro, que não esconde sua admiração pela "revolução de 1964" e pelo "regime militar" que se seguiu.

Em suma, a situação é complexa e polarizada, num crescendo desde 2013. Não há como ter clareza sobre seus desdobramentos no momento em que fecho a revisão deste artigo, logo após um grande movimento de caminhoneiros que paralisou o país por vários dias no final de maio de 2018, contra o aumento de preços dos combustíveis. Esses caminhoneiros também se beneficiaram das mudanças culturais e simbólicas dos últimos anos aqui mencionadas. Por exemplo, eles tiveram acesso a novas tecnologias, como telefones celulares e redes sociais: foi através do WhatsApp que organizaram o movimento, com uma presença expressiva de setores de extrema direita a pedir o retorno dos militares ao poder.

Os acontecimentos recentes - como a polêmica condenação de Lula pelo Judiciário no caso do "tríplex do Guarujá" e sua prisão em abril de 2018 - expressam o fim de um ciclo histórico cujo início simbólico pode ser sua primeira prisão, em 1980, em meio à greve de metalúrgicos que liderava no $\mathrm{ABC}$ paulista, desafiando a ditadura militar. Mas isso seria tema para um outro artigo. 